\title{
MAP SHOWING CITRATE-SOLUBLE HEAVY METALS IN STREAM SEDIMENTS, OSSIPEE LAKE QUADRANGLE, CARROLL COUNTY, NEW HAMPSHIRE \\ By \\ Dennis P. Cox
}

MISCELLANEOUS GEOLOGIC INVESTIGATIONS

MAP I-609

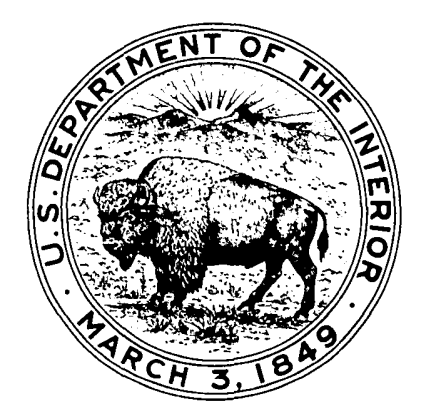

PUBLISHED BY THE U.S. GEOLOGICAL SURVEY 